Научная статья

УДК 343.98

DOI 10.18101/2658-4409-2021-3-46-53

\title{
ОСНОВЫ КРИМИНАЛИСТИЧЕСКОГО ОБЕСПЕЧЕНИЯ ДОСУДЕБНОГО СОГЛАШЕНИЯ О СОТРУДНИЧЕСТВЕ ПРИ РАССЛЕДОВАНИИ УГОЛОВНЫХ ДЕЛ О НЕЗАКОННОМ ОБОРОТЕ НАРКОТИКОВ
}

\author{
(C) Попова Елена Ильинична \\ научный сотрудник \\ popovaelena03@yandex.ru. \\ (C) Джебраилов Лятиф Гурбанали оглы \\ аспирант \\ latif.gurbanali@mail.ru
}

Бурятский государственный университет имени Доржи Банзарова Россия, 670000, г. Улан-Удэ, ул. Сухэ-Батора, 6

\begin{abstract}
Аннотация. Досудебное соглашение о сотрудничестве, несмотря на более чем десятилетний опыт своего применения, тем не менее остается одним из самых дискуссионных уголовно-процессуальных институтов и вызывает много вопросов у правоприменителей. Авторы предлагают обратить внимание на целесообразность заключения досудебного соглашения о сотрудничестве по уголовным делам о незаконном обороте наркотиков, а также разработке криминалистического обеспечения применения норм гл. 40.1 УПК РФ. В статье уделяется внимание понятию названного криминалистического обеспечения, его значению, приводятся некоторые рекомендации по его подготовке и реализации, обозначаются принципы расследования по уголовным делам рассматриваемого вида при заключении досудебного соглашения о сотрудничестве. Отмечается целесообразность введения элементов алгоритмизации деятельности следователей в рассматриваемом направлении.

Ключевые слова: незаконный оборот наркотиков, преступление, подозреваемый, обвиняемый, соглашение о сотрудничестве, криминалистическое обеспечение.
\end{abstract}

\section{Для цитирования}

Попова Е. И., Джебраилов Л. Г. Основы криминалистического обеспечения досудебного соглашения о сотрудничестве при расследовании уголовных дел о незаконном обороте наркотиков // Вестник Бурятского государственного университета. Юриспруденция. 2021. Вып. 3. С. 46-53.

В современной России, как и в мировом сообществе в целом, незаконный оборот наркотических средств и психотропных веществ, их аналогов выступает глобальной проблемой. Он напрямую связан с деятельностью организованной преступности, порождает совершение целого ряда различного рода преступных посягательств, способствуя росту количества наркозависимых лиц [1]. Данный вопрос чрезвычайно актуален: национальная статистика, представленная ФСКН (ныне ГУНК МВД), демонстрирует грандиозные масштабы распространения 
Е. И. Попова., Л. Г. Джебраилов. Основы криминалистического обеспечения досудебного соглашения о сотрудничестве при расследовании уголовных дел о незаконном обороте наркотиков

наркомании. Если в 2010 г. согласно данным официальной статистики наркозависимых было 26,4 тыс. человек, а в 2015 г. - 48,9 тыс., то в 2020 г. отмечен беспрецедентный рост как наркозависимых, так и лиц с психическими и поведенческими расстройствами, связанными с подобной зависимостью (около 460 тыс.) ${ }^{1}$.

Неутешительны и статистические показатели, характеризующие число преступлений, которые связаны с незаконным оборотом наркотиков. Так, в 2020 г. было выявлено более чем 30 тыс. подобных деяний, а объем конфискованных наркотических веществ и средств возрос в четыре раза; практически на $70 \%$ возросло число преступлений, которые имеют связь со сбытом запрещенных средств, веществ посредством высоких технологий, в том числе сети Интернет ${ }^{2}$.

Одним из действенных механизмов, используемых при расследовании преступлений, связанных с незаконным оборотом наркотиков, является заключение досудебного соглашения о сотрудничестве. Возможность его использования появилась в Российской Федерации в 2009 г. с принятием Федерального закона 29.06.2009 № 141-Ф333, которым внесены изменения в Уголовный кодекс РФ ${ }^{4}$ и в Уголовнопроцессуальный кодекс Р $\Phi^{5}$. В соответствии со ст. 5 УПК РФ досудебное соглашение о сотрудничестве заключается между сторонами обвинения и защиты в рамках расследования уголовных дел в форме письменного документа, в соответствии с которым стороны соглашения согласовывают условия взаимодействия в направлении сотрудничества и ответственности подозреваемого (обвиняемого), имеющие зависимость от действий данного лица как после возбуждения уголовного дела, так и после предъявления соответствующего обвинения. Ходатайство в отношении заключения соглашения (ст. 317.2 УПК РФ) подается на имя прокурора от имени подозреваемого (обвиняемого), подписывается приглашенным (либо обеспеченным со стороны государства) защитником.

В научном сообществе, преимущественно учеными-процессуалистами, названное досудебное соглашение определяется через категорию «договор», заключаемый между сторонами обвинения и защиты [2-4], и как «сделка, совершаемая с правосудием [5], а также как ненормативный правовой акт, признанный особой формой юридического закрепления определенных процессуальных действий, которые реализуются сторонами соглашения (обвинения и защиты) [6].

Отдельными правовыми особенностями характеризуется досудебное соглашение о сотрудничестве по уголовным делам в отношении незаконного оборота наркотиков. При этом эффективность соглашения достигается посредством криминалистического обеспечения, которое, по мнению известных криминалистов, представляет собой внедрение в процесс расследования уголовного дела в целях

\footnotetext{
${ }^{1}$ Статистика наркомании в России 2020-2021 г. URL: https://narcorehab.com (дата обращения: 11.05.2021). Текст : электронный.

2 Патрушев сообщил о росте смертности от наркотиков в центральной России. URL: https://www.interfax.ru/russia/734974 (дата обращения: 11.05.2021). Текст : электронный.

${ }^{3} \mathrm{O}$ внесении изменений в Уголовный кодекс Российской Федерации и Уголовнопроцессуальный кодекс Российской Федерации: федеральный закон от 29.06.2009 № 141-Ф3 // РГ. 2009. № 121. Текст : непосредственный.

${ }^{4}$ Уголовный кодекс Российской Федерации от 13 июня 1996 г. № 63-Ф3 // РГ. 1996. № 113, $114,115,118$. Текст : непосредственный.

5 Уголовно-процессуальный кодекс Российской Федерации от 18 декабря 2001 г. № 174-Ф3 // РГ. 2001. № 249. Текст : непосредственный.
} 
противодействия, выявления, равно как и раскрытия, расследования преступлений как теоретических криминалистических знаний, так и основанных на знаниях профессиональных навыков и умений сотрудников правоохранительных органов по использованию прикладных достижений криминалистической науки $[7,8]$. Криминалистическое обеспечение в направлении раскрытия и расследования уголовно-наказуемых деяний трактуется также в качестве системы динамической передачи такой информации, которой обеспечено применение криминалистического арсенала, направленного на противодействие преступности [9]. Данная категория определена также как комплекс разработанных криминалистикой средств, приемов, рекомендаций, технологий тактического, технического, методического, управленческо-организационного характера, позволяющих эффективно, качественно, оптимально и рационально осуществлять собирание, фиксацию, изъятие, исследование криминалистически значимой информации в зависимости от ситуации, ее использование с целью решения задач судопроизводства [10].

Взяв за основу позицию А. А. Белякова и Р. С. Хамидуллина, посвятивших свое исследование криминалистическому обеспечению заключения досудебного соглашения о сотрудничестве, и скорректировав мнение авторов применительно к заявленной нами проблематике, отметим следующее: структура такого криминалистического обеспечения по уголовным делам в сфере незаконного оборота наркотиков может быть представлена как система взаимосвязанных элементов, направленных на раскрытие и расследование наркопреступлений: во-первых, научно-методического, во-вторых, организационного, в-третьих, тактико-криминалистического и, в-четвертых, технико-криминалистического обеспечения. Предметом криминалистического обеспечения досудебного соглашения о сотрудничестве по делам анализируемой категории являются закономерности поведения представителей стороны защиты, иных заинтересованных в исходе дела лиц, противодействующих расследованию (уголовному преследованию), и основанные на познании этих закономерностей специальные средства и методы расследования и судебного разбирательства с использованием положений гл. 40.1. УПК РФ [9, с. 19-21].

Благодаря криминалистическому обеспечению возможно получить важную информацию о субъектах, предметах и объектах преступления, впоследствии являющихся предпосылкой для изобличения лиц, совершивших преступления анализируемого нами вида, для изъятия наркотических средств и психотропных веществ, другого имущества и др. Названные действия коррелируют с назначением уголовного судопроизводства (ст. 6 УПК РФ).

По мнению ряда исследователей (О. Я. Баев, А. А. Беляков, Р. С. Хамидуллин и др.), заключение досудебного соглашения о сотрудничестве и последующее расследование в порядке гл. 40.1 УПК РФ будут максимально эффективны при реализации одноименной криминалистической операции [12-15]. В ее рамках может быть решен комплекс важных тактических задач. В их числе можно назвать преодоление противодействия расследованию и последующему судебному разбирательству; выявление новых эпизодов преступной деятельности; формирование прочной и непротиворечивой доказательственной базы; повышение эффективности реального обеспечения законных интересов потерпевшего и другое. 
Е. И. Попова., Л. Г. Джебраилов. Основы криминалистического обеспечения досудебного соглашения о сотрудничестве при расследовании уголовных дел о незаконном обороте наркотиков

Важную роль в реализации рассматриваемой тактической операции играет взаимодействие следователя, оперативных сотрудников и работников прокуратуры, а также продуманное использование знаний криминалистики, умелое сочетание как технико-криминалистических, так и тактических средств, приемов и методов. Посредством тактической операции «Заключение досудебного соглашения о сотрудничестве по уголовным делам о незаконном обороте наркотиков» представляется возможным получить важную с криминалистической позиции информацию для расследования уголовного дела, впоследствии являющуюся предпосылкой для изобличения и привлечения к уголовной ответственности лиц, совершивших наркопреступление, для изъятия наркотических средств и психотропных веществ, других объектов, имущества.

Содержание соглашения не следует ограничивать как сотрудничеством исключительно в рамках получения сведений о месте хранения запрещенных средств и веществ наркотического характера, так и об изобличении путей их транспортировки и распространения. Представляется важным в рамках реализации соглашения о сотрудничестве использовать фактическую возможность в направлении розыска имущества посредством получения сведений о лицах, осуществляющих сбыт, об обстоятельствах приобретения средств и веществ, другого имущества, изъятого при обыске, равно как и при осмотре места происшествия или производстве выемки [16, с. 7].

Стимулом к подобному сотрудничеству выступает, прежде всего, предусмотренный действующим уголовным законодательством порядок применения уголовного наказания в пониженных пределах, другие «благоприятные» последствия, применяемые судом (это и условное осуждение, и применение наименее строгого наказания, чем установлено уголовным законом за данное деяние, освобождение от уголовного наказания, меры безопасности в отношении подозреваемого, обвиняемого).

Заключение соглашения о сотрудничестве позволяет обвиняемому улучшить свое положение, в том числе добиться назначения более мягкого наказания, по сравнению с тем, что могло было быть назначено без применения норм гл. 40.1 УПК РФ. В этой связи, например, О. Н. Тисен обоснованно отмечает, что правила о смягчении наказания увеличивают риск возникновения у названного субъекта умысла в отношении введения сотрудников правоохранительных органов в заблуждение [16, с. 117] о месте сокрытия запрещенных веществ, соучастниках, их роли в преступных посягательствах и т. п. Данный факт необходимо принимать во внимание сотрудникам правоохранительных органов при заключении соглашения.

Как отмечено А. К. Салыковой, реализация всех условий соглашения о сотрудничестве, рассматриваемое в контексте смягчения уголовного наказания, будет иметь место при совокупности следующих условий: соглашение заключено и утверждено в предусмотренном нормативном порядке; подозреваемый, обвиняемый, заключивший соглашение, добросовестно исполнил отраженные в нем обязательства; сотрудничество позволило изобличить преступников, обнаружить предметы преступления; в отношении виновных лиц вынесен обвинительный приговор [17, с. 18-19]. 
Представляется, что для оптимизации деятельности сотрудников правоохранительных органов по уголовным делам о незаконном обороте наркотиков необходимо:

- продолжение оснащения специалистов, осуществляющих криминалистическое обеспечение досудебного соглашения, инновационными механизмами, позволяющими наиболее качественно решать задачи, поставленные в рамках подобного обеспечения;

- расширить число вопросов, рассматриваемых в рамках повышения квалификации сотрудников правоохранительных органов, включив в нее вопросы по использованию научно обоснованных рекомендаций по применению норм гл. 40.1 УПК РФ;

- стимулировать сотрудников (премии) правоохранительных органов, которые наиболее эффективно используют для решения тактических задач расследования нормы закона, предусматривающие возможность заключения досудебного соглашения;

- предоставить сотрудникам правоохранительных органов больше возможностей к доступу персональной информации лиц, которые подозреваются в совершении незаконного оборота наркотиков, усовершенствовать в указанной связи взаимодействие правоохранительных органов с другими федеральными органами исполнительной власти.

Предлагаются следующие принципы криминалистического обеспечения досудебного соглашения в части взаимодействия представителей сторон обвинения и защиты по уголовным делам в сфере незаконного оборота наркотиков, которые необходимо учитывать при реализации данного правового механизма:

- принцип использования прогрессивных достижений криминалистической науки и техники;

- принцип эффективности применения криминалистических средств, приемов и методов на практике;

- принцип профессионализма сотрудников правоохранительных органов;

- принцип наступательности в расследовании [19];

- принцип компромисса [20];

- принцип обеспечения защиты прав и законных интересов обвиняемых.

Представляется возможным обратить внимание на возможность и необходимость алгоритмизации деятельности следователя, иных сотрудников правоохранительных органов в случае заключения досудебного соглашения о сотрудничестве по уголовным делам о незаконном обороте наркотиков. Под алгоритмизацией вслед за Е. П. Ищенко, Н. Б. Водяновой мы понимаем формирование направлений и создание целостной системы зависимых от следственной ситуации следственных и других действий, в том числе комплексы, выстроенные в целесообразной последовательности на основе заявленных приоритетов [21]. На наш взгляд, целесообразность заключения досудебного соглашения о сотрудничестве по делам о незаконном обороте наркотиков с несколькими лицами представляется возможной исключительно в ситуации, когда у данных подозреваемых (обвиняемых) различаются принятые в соглашении обязательства: в отношении изобличения соучастников; в отношении содействия в обнаружении наркотических средств и иных веществ и прочее. 
Е. И. Попова., Л. Г. Джебраилов. Основы криминалистического обеспечения досудебного соглашения о сотрудничестве при расследовании уголовных дел о незаконном обороте наркотиков

В заключение отметим, что криминалистическое обеспечение предварительного расследования по делам об обороте наркотиков представляет собой сформированный наукой криминалистикой инструментарий, арсенал, благодаря которому субъект поисковопознавательной сферы деятельности эффективно выстраивает, как стратегию, так и тактику расследования уголовного дела.

\section{Литература}

1. Буракова Е. Е., Кукса И. И. Понятие незаконного оборота наркотических средств и психотропных веществ // Elibrary.ru. 2020. № 32. C. 20-25. URL: https:// elibrary.ru/item.asp?id=42561759 (дата обращения: 11.05 .2021 ). Текст : электронный.

2. Смирнов А. В. Особый порядок принятия судебного решения при заключении досудебного соглашения о сотрудничестве // Уголовный процесс. 2009. № 10. С. 5-8. Текст : непосредственный.

3. Головинский М. М. Досудебное соглашение о сотрудничестве: нормативноправовое регулирование и практика применения : диссертация на соискание ученой степени кандидата юридических наук. Владимир, 2011. 240 с. Текст : непосредственный.

4. Хромова Н. М. Особый порядок судебного разбирательства как процессуальный договор // Российский судья. 2019. № 5. С. 60-64. Текст : непосредственный.

5. Агаев 3. Р. Правовое регулирование досудебного соглашения в России // Адвокат. 2010. № 9. С. 12-17. Текст : непосредственный.

6. Строганова Т. Ю. Понятие и признаки досудебного соглашения о сотрудничестве // Российский судья. 2018. № 7. С. 28-32. Текст : непосредственный.

7. Коломацкий В. Г. Криминалистическое обеспечение деятельности органов внутренних дел по расследованию преступлений // Криминалистика. Москва, 1995. Т. 1.411 с. Текст : непосредственный.

8. Белкин Р. С., Аверьянова Т. В. Криминалистическое обеспечение деятельности криминальной милиции и органов предварительного расследования : учебник. Москва, 1997. 398 с. Текст : непосредственный.

9. Беляков А. А., Хамидуллин Р. С. Понятие и содержание криминалистического обеспечения расследования уголовных дел при заключении досудебного соглашения о сотрудничестве // Вестник Уральского юридического института МВД РОССИИ. 2016. № 3. С. 18-24. Текст : непосредственный.

10. Митрофанова А. А. К вопросу об определении понятия «криминалистическое обеспечение» // Сибирские уголовно-процессуальные и криминалистические чтения. 2017. № 4. С. 188-195. Текст : непосредственный.

11. Баев О. Я. Досудебное соглашение о сотрудничестве: правовые и криминалистические проблемы, возможные направления их разрешения : монография. Москва : Норма ; ИНФРА-М, 2013. С. 22-34. Текст : непосредственный.

12. Хамидуллин Р. С. Понятие и содержание тактической операции «Привлечение подозреваемого (обвиняемого) к сотрудничеству путем заключения досудебного соглашения о сотрудничестве» // Юридическая наука и правоохранительная практика. 2017. № 41(3). С. 149-156. Текст : непосредственный.

13. Попова Е. И., Асалханов Т. Ю. Основы тактической операции «заключение с подозреваемым (обвиняемым) досудебного соглашения о сотрудничестве» 
по уголовным делам об убийствах // Вестник Дальневосточного юридического института МВД России. 2019. № 2(47). С. 111-116. Текст : непосредственный.

14. Попова Е. И., Гаджиев В. Э Основы тактической операции «Досудебное соглашение о сотрудничестве по уголовным делам о хищениях скота» // Полицейская и следственная деятельность. 2019. № 3 С. 1-8. Текст : непосредственный.

15. Родин В. В. Особенности проведения криминалистической операции по заключению досудебного соглашения о сотрудничестве по преступлениям, связанным с незаконным оборотом наркотических и психотропных веществ // Концепт. 2014. Спецвып. № 29. С. 1-7. Текст : непосредственный.

16. Тисен О. Н. Актуальные проблемы использования института досудебного соглашения о сотрудничестве по уголовным делам в сфере незаконного оборота наркотических средств // Вестник Сибирского юридического института ФСКН России. 2016. № 3(23) С. 116-120. Текст : непосредственный.

17. Салыкова А. К. Назначение наказания при досудебном соглашении о сотрудничестве (соглашении о сотрудничестве) по уголовному законодательству Российской Федерации и Республики Казахстан : автореферат диссертации на соискание ученой степени кандидата юридических наук. Омск, 2021. 229 с. Текст : непосредственный.

18. Гармаев Ю. П. Принцип наступательности в выявлении и расследовании преступлений // Российский следователь. 2016. № 2. С. 6-12. Текст : непосредственный.

19. Попова Е. И. О необходимости создания криминалистических методик на основе принципа компромисса // Lex russica. 2017. № 9(130). С. 107-116. Текст : непосредственный.

20. Ищенко Е. П., Водянова Н. Б. Алгоритмизация следственной деятельности. Москва, 2010. С. 59-60. Текст : непосредственный.

Статья поступила в редакиию 10.09.2021; одобрена после рецензирования 13.10.2021; принята к публикации 08.11.2021.

\section{FUNDAMENTALS OF THE CRIMINAL ENFORCEABILITY OF PLEA AGREEMENT IN INVESTIGATING CRIMINAL CASES ON ILLEGAL DRUG TRAFFICKING}

Elena I. Popova

Researcher

popovaelena03@yandex.ru

Latif G. Dzhebrailov

Research Assistant

latif.gurbanali@mail.ru

Dorzhi Banzarov Buryat State University

6 Sukhe-Batora St., Ulan-Ude 670000, Russia 
Е. И. Попова., Л. Г. Джебраилов. Основы криминалистического обеспечения досудебного соглашения о сотрудничестве при расследовании уголовных дел о незаконном обороте наркотиков

Abstract. Despite more than a decade of plea agreement application, it remains one of the most controversial criminal procedural institutions and raises many questions from law enforcement officers. We have paid attention to the expediency of plea agreements in the criminal cases on illegal drug trafficking, and criminal enforcement of Part 40.1 of the Criminal Procedure Code of the Russian Federation. The article focuses on the concept of criminal enforcement, its meaning, provides some recommendations for its preparation and implementation, regards the principles of investigating the criminal cases of the type under consideration when taking a plea. It is noted the expediency of introducing elements of algorithmic activity of investigators in this direction.

Keywords: illegal drug trafficking, crime, the suspect, the accused, immunity agreement, criminal enforceability.

\section{For citation}

Popova E. I., Dzhebrailov L. G. Fundamentals of the Criminal Enforceability of Plea Agreement in Investigating Criminal Cases on Illegal Drug Trafficking. Bulletin of Buryat State University. Law. 2021; 3: 46-53 (In Russ.).

The article was submitted 10.09.2021; approved after reviewing 13.10.2021; accepted for publication 08.11.2021. 